\title{
The Journal - a Critical Development in the Professional Journey of the College
}

In the professional journey of the College in February 2006 I was a participant in early meetings of a Federal Councilendorsed Steering Committee to develop the College's own professional journal.

The thinking behind this initiative centred on the fundamental belief that a professional body should have, under its auspices, a peer reviewed professional journal with a focus on its particular body of knowledge.

Events that took place in the preceding twenty years, had led to this step.

In 1990 the College was created with a new Memorandum and Articles of Association that saw the former Australian Institute of Hospital Administrators become the Australian College of Health Service Administrators. That body subsequently became the Australian College of Health Service Executives (ACHSE).

The key shift in the 1990s was to move from the role of an Institute to that of a College. A College required a greater focus on a body of knowledge and expanded academic and continuing professional learning.

A College also warranted clearer assessment processes for an individual member's entry, advancement and ongoing standing within it.

As these developments took place, ACHSE and SHAPE (Society of Health Administration Programs in Education) also worked closely together to give impetus to both organisations in their objective to formalise material for that body of knowledge. ACHSE also reviewed its consultation mechanisms and procedures supporting its activities to accredit formal academic programs in health services management.

In a parallel series of developments, commenced in the 1980s, ACHSE made positive efforts to strengthen its relationships with existent and early stage health service management bodies in the Asia Pacific region.

In 1996 Memoranda of Understanding were created between ACHSE and the New Zealand Institute of Health Management as well as with the Hong Kong Society of Health
Service Executives. Formal liaison was also established with the Indonesian Association of Health Service Managers and with those involved in the early developments to form similar bodies in Malaysia, New Guinea and Thailand.

An ACHSE professional journal thus had two potential roles. One to be the College's necessary professional publication that was conducted in close association with its academic partners, to develop its body of knowledge. The other was potentially to become a vehicle to help draw together the health management professional bodies in the Asia Pacific region.

So in February 2006, representatives of Federal Council, SHAPE, National Office staff and interested members came together to develop the proposed College journal.

The meeting presented several outcomes for Federal Council to consider. Firstly, a plan to publish a first edition in 2006 was proposed. Secondly, the title for the new journal was suggested as the Asia Pacific Journal of Health Management (APJHM). The supporting infrastructure was conceived as an Honorary Editor supported by an Editorial Committee and an overarching Journal Advisory Committee. Calls for expressions of interest for Peer Reviewers were proposed as well as a call for papers. Federal Council adopted these recommendations.

The most significant outcomes, however, from this Steering Committee for Federal Council to consider, were the recommendation to approach Dr Mary Harris to become Foundation Honorary Editor and the proposal for Carolyn Marsh, then the senior staff member in the National Office, and Rose Ellis an experienced person in journal publication, to work together on producing the journal.

Mary's thorough and skilled efforts as Foundation Editor were of the same order as all her other many significant contributions to the College and SHAPE over many years. In 2002 Mary had been awarded the prestigious ACHSE Gold Medal for her many contributions to the profession of health services management. She was simply outstanding in the APJHM Editor's role through her personal abilities and hard work. Previously Mary provided leadership and impeccable 
coordination to the producing and editing of the significant SHAPE/ACHSE text book Health Service Management: Concepts and Practice, which in its first two editions received wide acclaim.

The text became a major resource for Australian and New Zealand health management practitioners and students. Her efforts as APJHM Foundation Editor were of the same order. She was an inspired nomination. Another ACHSE Gold Medal winner followed Mary Harris as Honorary Editor in the form of David Briggs. David has been one of the really exceptional leaders of the College, with continuing contributions now extending over a forty year period. National Presidency, the development of South East Asian linkages, valuable academic and health governance contributions plus significant roles in achieving initiatives such as the formation of the NSW Aboriginal Health Management Training Program, have been part of David's ACHSE career. He has continued his fine efforts for the College with his highly effective and thoughtful Honorary Editor role of APJHM.

The Journal has become open access, available freely to all members and non members alike. For those not aware of the College, it is accessible through Informit and EBSCO Research Databases. Endeavours continue to be made to extend listings as the APJHM meets the relevant criteria. Interestingly it is now attracting authors and reviewers engaged in the health system, but not previously involved with the College.

Now, ten years on from the ambitious agenda developed by the Steering Committee in 2006, the APJHM is the keystone in an overarching structure that links academic and professional practitioner interests across the Asia-Pacific geography and will continue to define much of Australia's future.

In more recent times the Board of the College has moved to strengthen the focus on knowledge in health service management as the fundamental focus of the organisation. The College is now named the Australasian College of Health Service Management. Its title is unambiguously on the 'What' of the profession of health service management. The organisation's geographic membership coverage is now declared as the wider span of the Asia Pacific region. I was privileged to have worked for some ten years, prior to 2006, as a part time National Director of the College. and to have been part of launching the first steps that created the APJHM.
Federal Council, however, supported my request in early 2006 for leave of absence to go to Canberra to serve for six months as the Interim CEO of the National Health and Medical Research Council. Other opportunities for roles with the Australian Commission on Safety and Quality in Health Care arrived at the end of that time and I did not return to the College.

My expectations, in 2006, for the introduction and development of a College professional journal have been more than met by the efforts of Mary Harris, David Briggs and all associated with the Asia Pacific Journal of Health Management.

Congratulations to all involved, and to the then Federal Council and now the Board of the College, for their far sighted and ongoing support for this fundamentally vital element of a professional body's offerings.

\section{Bill Lawrence AM}

Life Member, ACHSM 